\title{
The consequences of declining population access to insecticide-treated nets (ITNs) on net use patterns and physical degradation of nets after 22 months of ownership
}

Zawadi M. Mboma ${ }^{1,2^{*}}$ (i), Charles Festo ${ }^{1}$, Lena M. Lorenz ${ }^{1,2,3}$, Dennis J. Massue ${ }^{4,5,6,7}$, William N. Kisinza ${ }^{8}$, John Bradley ${ }^{9}$, Jason D. Moore ${ }^{4,5}$, Renata Mandike ${ }^{10}$, Ikupa Akim ${ }^{5}$, Jo Lines ${ }^{2}$, Hans J. Overgaard ${ }^{11,12}$ and Sarah J. Moore $4,5,6$

\begin{abstract}
Background: As insecticide-treated nets (ITNs) wear out and are disposed, some household members are prioritized to use remaining ITNs. This study assessed how nets are allocated within households to individuals of different age categories as ITNs are lost or damaged and as new ITNs are obtained. The study also explored how ITN allocation affects ITN durability.

Methods: A cross-sectional household survey and ITN durability study was conducted among 2,875 households across Tanzania to determine the proportion of nets that remain protective (serviceable) 22 months after net distribution aiming for universal coverage. Allocation of study nets within houses, and re-allocation of ITNs when new universal replacement campaign (URC) nets arrived in study households in Musoma District, was also assessed.

Results: Some $57.0 \%$ (95\% Cl 53.9-60.1\%) of households had sufficient ITNs for every household member, while $84.4 \%$ (95\% Cl 82.4-86.4\%) of the population had access to an ITN within their household (assuming 1 net covers every 2 members). In households with sufficient nets, $77.5 \%$ of members slept under ITNs. In households without sufficient nets, pregnant women (54.6\%), children $<5$ years (45.8\%) and adults (42.1\%) were prioritized, with fewer school-age children 5-14 years (35.9\%), youths 15-24 years (28.1\%) and seniors $>65$ years (32.6\%) sleeping under ITNs. Crowding ( $\geq 3$ people sleeping under nets) was twice as common among people residing in houses without sufficient nets for all age groups, apart from children $<5$. Nets were less likely to be serviceable if: $\geq 3$ people slept under them (OR 0.50 (95\% Cl 0.40-0.63)), or if nets were used by school-age children (OR 0.72 ( $95 \% \mathrm{Cl} 0.56-0.93)$ ), or if the net product was Olyset ${ }^{\circledR}$. One month after the URC, only $23.6 \%$ (95\% Cl 16.7-30.6\%) of the population had access to a URC ITN in Musoma district. Householders in Musoma district continued the use of old ITNs even with the arrival of new URC nets.
\end{abstract}

Conclusion: Users determined the useful life of ITNs and prioritized pregnant women and children $<5$ to serviceable ITNs. When household net access declines, users adjust by crowding under remaining nets, which further reduces ITN lifespan. School-age children that commonly harbour gametocytes that mediate malaria transmission are compelled to sleep under unserviceable nets, crowd under nets or remain uncovered. However, they were accommodated by

\footnotetext{
*Correspondence: zmageni@ihi.or.tz

${ }^{1}$ Ifakara Health Institute, Dar es Salaam, Tanzania

Full list of author information is available at the end of the article
}

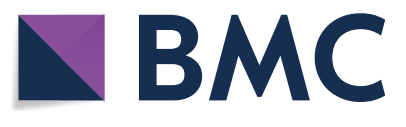

(c) The Author(s) 2021. This article is licensed under a Creative Commons Attribution 4.0 International License, which permits use, sharing, adaptation, distribution and reproduction in any medium or format, as long as you give appropriate credit to the original author(s) and the source, provide a link to the Creative Commons licence, and indicate if changes were made. The images or other third party material in this article are included in the article's Creative Commons licence, unless indicated otherwise in a credit line to the material. If material is not included in the article's Creative Commons licence and your intended use is not permitted by statutory regulation or exceeds the permitted use, you will need to obtain permission directly from the copyright holder. To view a copy of this licence, visit http://creativeco mmons.org/licenses/by/4.0/. The Creative Commons Public Domain Dedication waiver (http://creativecommons.org/publicdomain/ zero/1.0/) applies to the data made available in this article, unless otherwise stated in a credit line to the data. 
the arrival of new nets. More frequent ITN delivery through the school net programme in combination with mass distribution campaigns is essential to maximize ITN effectiveness.

Keywords: Insecticide-treated nets (ITNs), Population access, Serviceability, Crowding, Net use, Malaria

\section{Background}

Insecticide-treated nets (ITNs) are impactful in the fight against malaria in sub-Saharan Africa [1]. In Tanzania, mass distribution campaigns of ITNs have been conducted every four years, in 2010-2011 and 2015-2016 $[2,3]$. Through mass distribution, coupled with targeted campaigns, approximately 70 million ITNs have been distributed in Tanzania since 2010 [2-6], resulting in a 12\% reduction in malaria deaths and $15 \%$ reduction in cases per capita at risk $[7,8]$. These gains against malaria in Tanzania can also be attributed to early implementation of successful behavioural change communication that has encouraged appropriate and sustained net use among populations at risk of malaria [9].

Effective malaria protection by ITNs is achieved when at least $80 \%$ of household members have access to, and sleep under ITNs [10]. The World Health Organization (WHO) recommends the combination of mass campaigns and targeted mechanisms to ensure continued universal coverage of at least one ITN to cover every two people in a household, for all populations in malariaendemic countries irrespective of age or gender [11]. To account for differences in household size, one net for every 1.8 persons is recommended during procurement to ensure universal access to ITNs within households [12]. Despite best efforts, population access to ITNs (the percentage of the population with access to an ITN within their household, assuming each ITN is used by 2 people) remains below the target level of $80 \%$ in many malaria-endemic areas [13]. According to the 2017 Tanzania Malaria Indicator Survey (TMIS), 63\% of the population had access to an ITN while only $52 \%$ slept under an ITN the previous night [14]. ITN access in Tanzania has remained around 50\% since 2010 with peak access of $75 \%$ in 2011 and 63\% in 2017 after mass distribution of ITNs [14]. Access to ITNs tends to generally be high after mass distribution but falls rapidly as nets wear out [15]. With time and use, ITNs in households get damaged and when they are no longer perceived to be useful, they are discarded by householders [16-19], resulting in lower population access to nets [20]. Moreover, an ITN is only effective for as long as it remains serviceable, i.e., sufficiently intact to provide adequate personal protection against malaria [21]. There is good evidence that when used, ITNs provide personal protection against malaria even in areas of high mosquito resistance to insecticide [22]. Therefore, it is important to understand underlying reasons for the loss of nets from households and reasons why they may not be used in order to maximize longevity and use of existing ITNs in Tanzania.

There are several factors that affect ITN access and use, including household size [23], user characteristics: age, gender, pregnancy status [24-26], and socio-economic status (SES) [27]. As nets wear out and access to nets declines, it is likely that households will prioritize who will use remaining net(s) based on the number of net(s) currently available in the household and their condition [28-30]. Potential consequences of prioritization could be (1) crowding, i.e., more than the two household members assumed to share a net, sleeping under the same net; and/or, (2) some household members being left uncovered. It is important for national malaria control programmes (NMCPs) in malaria-endemic countries to understand how households decide on who to prioritize for bed-net use within households, so they can inform behavioural change communication strategies, design targeted ITN delivery mechanisms for at-risk groups or, if needed, increase the frequency of mass ITN campaigns. This study assessed how nets are allocated within households to individuals of different age categories as ITNs become lost or damaged, and as new ITNs are obtained. In addition, it explores how ITN allocation among houses without sufficient ITNs further impacts ITN durability.

\section{Methods}

In 2015, a cross-sectional household survey was conducted in 2,875 households across eight districts. The survey was conducted between October and December just before the short rainy season when malaria transmission is usually low. The households randomly received one type of ITN from a pool of 3 products (referred hereafter as study nets): Olyset ${ }^{\circledR}$, NetProtect ${ }^{\circledR}$, PermaNet $^{\circledR}$, to cover every sleeping space identified during enrolment in 2013. Participating households were also geo-referenced using global positioning systems (GPS) during enrolment to aid identification during follow-up visits. Study nets were identifiable by their colour (white) and with a durable waterproof label to allow longitudinal follow-up. The average number of sleeping spaces per household among the study population was 3.1 and each household received an average of 3 study nets. Study-net dimensions were of double size $(190 \mathrm{~cm} \times 180 \mathrm{~cm} \times 150 \mathrm{~cm})$ assumed to fit 2 people under each net, similar to those distributed by the NMCP (Ikupa Akim, pers. comm). 
Data were generated as part of a longitudinal ITN durability study with three data collections $(10,22$ and 36 months) [31, 32] but data presented here are from the survey conducted 22 months (approximately 2 years) after ITN distribution, which coincided with the government's universal replacement campaign (URC) in 2015 (of which this study was not aware during protocol development), creating an opportunity to see how nets are allocated as new nets are received among households. The URC took place in Musoma, one of the 8 study districts, one month prior to the study survey. PermaNet ${ }^{\circledR}$ 2.0 was the net product distributed during the URC with a maximum of 5 ITNs distributed per household among households with 10 or more members (Ikupa Akim, pers. comm). PermaNet ${ }^{\circledR} 2.0$ ITNs distributed by the URC were identifiable by their blue colour. Additional nets (non-study nets) acquired by household members within those 22 months (regardless of their source) were assessed and all ITNs were included in the analysis. Data were collected using a questionnaire (Additional file 1) on (1) household members and their characteristics (age, gender, pregnancy status, SES); (2) access to and net use, including number of people sleeping under a net the previous night; and, (3) the physical status (serviceability) of a maximum 3 study nets per household. Data were collected using Google Nexus tablets, uploaded and sent to the Ifakara Health Institute servers at the end of each day. Both the data and project managers reviewed data continuously as every district was completed to assess and ensure quality and completeness.

\section{ITN physical degradation (serviceability)}

Over time, nets become torn with repeated use. While the inclusion of pyrethroid insecticides helps to prevent mosquitoes entering nets to some extent [33], the more holes in a net, the more mosquitoes will enter the net and reduce the protection given to a net user [34]. It is important to understand how much of the net surface area is available for mosquitoes to pass through. This is often done using a standard metric, the proportionate hole index (pHI), which provides an easy means of comparing this damage by calculating the approximate holed surface area of the net. All study nets had a unique barcode and were identifiable by which household they were distributed [31]. The study assessed the physical condition of a maximum of 3 (the average number of nets distributed per household) randomly selected study nets (by barcode) per household. The number and size of holes was assessed at household level using a portable frame [31], following WHO hole categorization [35]. The pHI was calculated for each ITN, and thereafter categorized as either serviceable ( $\mathrm{pHI}$ : $0-642)$ or unserviceable $(\mathrm{pHI}$ : $643+$ ). A net that is defined as unserviceable has been shown to offer reduced protection from mosquito bites and malaria [36].

\section{Net prioritization}

An in-depth assessment of some of the Roll Back Malaria Monitoring and Evaluation Reference Group (MERG) indicators [37, 38] as well as characteristics of ITN users (Table 1), was performed by the study team in all 8 study districts to understand: (1) which users (age category, gender, pregnancy status) were prioritized when ITNs are lost or damaged; and, (2) how ITN allocation among houses without sufficient ITNs further impacts ITN durability (age, number of occupants). Data from Musoma where the URC had been conducted were used to understand which users (age, gender, pregnancy status) were prioritized for the allocation of new nets and which users continued to use the older 'study nets'. Age categories in years were: children under the age of 5 , school-age children 5-14, youth 15-24, adults 25-65, and seniors $65+$.

\section{Statistical analysis}

Data analysis was carried out using statistical software package STATA 14.1 (StataCorp LP, College Station, TX, USA). Survey weights were used to compensate for unequal sampling units, adjust for non-response, and a multi-level modelling approach. Net use and the proportion of serviceable and unserviceable study nets by user age category, among houses with and without enough nets for every 2 members, are presented as frequencies and percentages. Statistical analysis of the effect of

Table 1 Roll Back Malaria Monitoring and Evaluation Reference Group ITN indicators assessed [37, 38]

\begin{tabular}{ll}
\hline ITN indicator & Indicator description \\
\hline Household with enough ITNs & Percentage of households with at least 1 ITN for every 2 people \\
Population access & Percentage of the population with access to an ITN within their household (assuming each net is used by 2 people) \\
Population ITN use & Percentage of the population that used an ITN the previous night \\
ITN use: access ratio & $\begin{array}{l}\text { Percentage of the population that used an ITN the previous night divided by the percentage of the population that } \\
\text { had access to an ITN }\end{array}$ \\
\hline
\end{tabular}


crowding (more than 2 people sleeping under a net) on net serviceability was done using logistic regression models with crowding as the main exposure. Other predictor variables specified a priori were user characteristics (age, gender), SES and net product. A forward-selection procedure was applied for modelling and the selection was based on change in main exposure effect estimate (mean square error). The procedure involved three main steps: (a) descriptive analysis and preliminary investigations for association between variables while paying attention to the sizes of effects as well as two-sided p-values at 95\% significance level; (b) variables selection: from prior knowledge, age and gender were considered as forced variables in the model. Then, one variable at a time from a list of candidate variables obtained from univariate analysis was included in the model with and without adjustment of forced variables to understand the effect of forced variables. The choice of the 'best' predictor to be included in the model was then decided based on the change in exposure effect estimate. Each time a new variable was added in the model, evidence of confounding and multicollinearity was assessed by comparing the effect estimates and standard errors between the 'univariate' and 'multivariate' models estimates; and, (c) multivariable models were fitted by adding explanatory variables that were removed from the models in step (b), one at a time to explore their effect when added to the model in presence of other variables in the model. Variables that resulted in positive changes in the mean square error were then included in the model. The process was repeated until all variables that provided precise estimates of exposure variables were selected.

\section{Results}

A total of 3096 households were re-visited from the 8 participating study districts of which 2875 were interviewed yielding a response rate of $92.9 \%$. Of the 221 households not interviewed, 110 households withdrew from the study as they had moved away from the study village, 70 householders were temporarily unavailable (in farms), while 41 households withdrew consent to continue to participate. Mosquito nets were found in 2801 (97.4\%) households of which 1668 (58.0\%) had study nets, 1126 (39.2\%) had both study and non-study nets, and 7 households $(0.2 \%)$ had non-study nets. Overall, 9178 mosquito nets were found, of which 5899 were in households with sufficient ITNs and 3288 in households without sufficient ITNs. Of these mosquito nets, 6938 (75.6\%) were identified as study nets and $2249(24.5 \%)$ as non-study nets since they were obtained from other sources. Of the nonstudy nets, $712(31.7 \%)$ were identified as ITNs based on their product label. Therefore, a total of 7650 ITNs (study and non-study) were identified and included in the analyses presented.

\section{ITN access}

In 2013, as part of the study design, $100 \%$ of sleeping spaces were covered by study nets, and this fell to $42.6 \%$ of sleeping spaces covered by study nets after 22 months. Including study nets and non-study ITNs, 57\% (95\% CI: 53.9-60.1\%) of the participating households still had sufficient ITNs, i.e., one ITN for every 2 household members assuming each ITN is used by 2 people. Eighty-four per cent (95\% CI: $82.4-86.4 \%)$ of the population living in the participating households had access to an ITN, assuming each ITN was used by 2 people, and $53.2 \%$ (95\% CI: 52.4-54.0\%) of those with access used an ITN the previous night (Table 2). Population access to ITNs among larger households ( $>10$ household members) was 79.0\% (95\% CI: 72.7-85.4\%) while in smaller households ( $\leq 10$ household members) was $93.2 \%$ (95\% CI: 91.8 $94.5 \%)$. The data are broadly similar to data collected by the TMIS, 2 years after the URC, indicating that ITNs last around 2 years in Tanzania (Table 2).

\section{The effect of household access on ITN prioritization}

Pregnant women and children under 5 years were most likely to sleep under an ITN irrespective of the household's ITN access, while young adults (15-24 years) contributed the lowest percentage of ITN users (Fig. 1a). Household access to nets clearly affected how nets were allocated within households. In houses with enough nets, $77.5 \%$ of members slept under ITNs compared to $37.5 \%$ of members in households without enough nets. There was prioritization for children $<5$ and pregnant women in both access scenarios, but in houses without sufficient nets this prioritization was more pronounced (Fig. 1a).

In households with enough nets, $91.1 \%$ of pregnant women slept under ITNs, $13.6 \%$ higher than the household average of $77.5 \%$ use. In houses without enough nets, a $17 \%$-point increase in net use among pregnant women was observed when compared to the average household use (54.6 vs 37.4\%). For children $<5$, 82.9\% slept under an ITN, 5.4\% higher than the household average of $77.5 \%$. In houses without enough nets, $45.8 \%$ of children $<5$ slept under ITNs, which is $8.4 \%$ higher than the household average use of $37.4 \%$. A slightly smaller proportion of children 5-14 years slept under ITNs compared to the household average in both houses with enough nets (75.7 vs 77.5\%) and in households without enough nets (35.9 vs 37.4\%). Youths were also less likely to be prioritized to ITNs in houses with enough nets $(5 \%$ lower than household average) and this was more pronounced in houses without enough nets $(9.3 \%$ lower than 
Table 2 Comparison of ITN use and access indicators across study districts in 2015, 2 years after study ITN distribution versus Tanzania Malaria Indicator Survey in 2017, 2 years after the universal replacement campaign

\begin{tabular}{|c|c|c|c|c|c|c|c|c|}
\hline \multirow[b]{2}{*}{ District } & \multicolumn{2}{|c|}{ Households with enough ITNs } & \multicolumn{2}{|c|}{ Population Access to ITNs } & \multicolumn{2}{|c|}{ Population ITN use } & \multicolumn{2}{|c|}{ ITN use:access ratio } \\
\hline & Study** & $\begin{array}{l}\text { Malaria Indicator } \\
\text { Survey }^{* \star *}\end{array}$ & Study** & $\begin{array}{l}\text { Malaria Indicator } \\
\text { Survey }\end{array}$ & Study** & $\begin{array}{l}\text { Malaria Indicator } \\
\text { Survery }\end{array}$ & Study** & $\begin{array}{c}\text { Malaria Indicator } \\
\text { Survey }\end{array}$ \\
\hline \multirow{2}{*}{ Bagamoyo } & 61.1 & \multirow{2}{*}{$61.8 \%$} & 82.7 & \multirow{2}{*}{$76.5 \%$} & 63.5 & \multirow{2}{*}{$83.7 \%$} & \multirow{2}{*}{0.76} & \multirow{2}{*}{1.09} \\
\hline & $(54.1-67.8)$ & & $(78.2-86.9)$ & & $(61.3-65.6)$ & & & \\
\hline \multirow{2}{*}{ Geita } & 40.8 & \multirow{2}{*}{$26.8 \%$} & 70.3 & \multirow{2}{*}{$51.5 \%$} & 47.6 & \multirow{2}{*}{$78.0 \%$} & \multirow{2}{*}{0.68} & \multirow{2}{*}{1.51} \\
\hline & $(34.2-47.9)$ & & $(66.0-74.7)$ & & $(45.7-49.6)$ & & & \\
\hline \multirow{2}{*}{ Iringa } & 71.2 & \multirow{2}{*}{$36.8 \%$} & 87.7 & \multirow{2}{*}{$55.2 \%$} & 57.4 & \multirow{2}{*}{$78.1 \%$} & \multirow{2}{*}{0.66} & \multirow{2}{*}{1.41} \\
\hline & $(64.4-77.2)$ & & $(83.4-91.9)$ & & $(55.0-59.8)$ & & & \\
\hline \multirow{2}{*}{ Kahama } & 48.1 & \multirow{2}{*}{$28.0 \%$} & 72.9 & \multirow{2}{*}{$49.1 \%$} & 42.6 & \multirow{2}{*}{$65.9 \%$} & \multirow{2}{*}{0.58} & \multirow{2}{*}{1.34} \\
\hline & $(38.7-57.7)$ & & $(66.4-79.4)$ & & $(40.8-44.5)$ & & & \\
\hline \multirow{2}{*}{ Kilosa } & 61.8 & \multirow{2}{*}{$57.5 \%$} & 83.8 & \multirow{2}{*}{$73.7 \%$} & 62.3 & \multirow{2}{*}{$76.7 \%$} & \multirow{2}{*}{0.74} & \multirow{2}{*}{1.04} \\
\hline & $(57.8-65.6)$ & & $(80.9-86.7)$ & & $(60.0-64.5)$ & & & \\
\hline & 53.6 & & 75.1 & & 47.1 & & & \\
\hline Kinondoni & $(46.4-60.7)$ & $55.3 \%$ & $(67.2-83.0)$ & $70.8 \%$ & $(43.6-50.5)$ & $78.2 \%$ & 0.63 & 1.10 \\
\hline & 56.4 & & 79.4 & & 32.1 & & & \\
\hline Mbozi & $(49.8-62.8)$ & $47.7 \%$ & $(74.3-84.4)$ & $61.9 \%$ & $(30.0-34.3)$ & $44.6 \%$ & 0.4 & 0.72 \\
\hline & 61.8 & & 86 & & 71.2 & & & \\
\hline Musoma & $(56.5-60.1)$ & $46.9 \%$ & $(83.2-88.7)$ & $71.8 \%$ & $(69.3-72.9)$ & $69.1 \%$ & 0.83 & 0.96 \\
\hline Total & 57.0 & $454 \%$ & 84.4 & 625 & 53.2 & $667 \%$ & 0.63 & 106 \\
\hline Iotal & $(53.9-60.1)$ & $40.4 \%$ & $(82.4-86.4)$ & 02.5 & $(52.4-54.0)$ & $60.1 \%$ & 0.03 & 1.00 \\
\hline
\end{tabular}

* Assuming each net is used by 2 people

** Denominator is 7650 ITNs (study and non-study ITNs) found in all participating households

*** Findings from the 2017 Tanzania Malaria Indicator Survey (TMIS)[14]

${ }^{* * * *}$ Colour codes for use: access ratio: Green = good $(\geq 0.80)$; Yellow = below target level $(\geq 0.60-<0.80)$; Red $=$ poor $(<0.60)$

household average). Seniors were less likely to be prioritized to ITN use in houses without enough ITNs, with only $32.6 \%$ of them sleeping under nets which was $4.8 \%$ lower than the household average, although this was not seen in houses with sufficient ITNs.

The variation observed in net use across user categories was related to sleeping space allocations. In descending order: seniors, youths and adults reported the highest percentages of users that slept alone under a net irrespective of whether the household had or did not have enough nets (Fig. 1b). Children under the age of 5 and pregnant women were most likely to share a net with another sleeper (Fig. 1b).

\section{The effect of household access on the number of people sleeping under an ITN}

A total of 2177 households (1,314 with and 863 without enough ITNs) had ITNs that were used the previous night. Of the 3,288 mosquito nets found in households without enough ITNs, $25.1 \%$ (95\% CI: $23.0-27.3 \%)$ were used by 3 sleepers, while $8.8 \%$ (95\% CI: $8.0-9.7 \%$ ) of the 5,899 nets found in households with enough ITNs were used by 3 or more people. The proportion of 3 or more household members sleeping under one net was higher in households without enough ITNs $(62.1 \%$ (95\% CI:
60.7-63.6\%) compared to those with enough ITNs [30.5\% (95\% CI: 29.2-31.7\%) (Table 3)]. Similarly, use: access ratio of $>1$, which implies more than 2 people slept under these ITNs [23], was observed in the majority of districts during the TMIS, and was more pronounced in Geita, Iringa and Kahama districts which had lower proportions of houses with sufficient ITNs (Table 2). When the population net use by 3 or more sleepers was explored by age category, the trend of crowding in households without enough nets doubled that of households with enough nets for all age categories except for children $>5$ who are more likely to sleep with their parents (Table 3 ).

\section{ITN serviceability}

Holes were counted in 4783 (68.9\%) of the 6938 study nets, 22 months after distribution. Of these, 3735 (78.1\%) nets were still serviceable while 1,048 (21.9\%) were unserviceable. Only $3622(75.7 \%)$ of the 4783 ITNs assessed for physical damage were used the previous night. Furthermore, $847(80.8 \%)$ of unserviceable nets and 2775 $(74.3 \%)$ of serviceable nets were used last night. Prioritization of serviceable nets was also observed. On average, $32.6 \%$ people slept under serviceable ITNs the previous night whereby around 7\% more pregnant women (40.5\%), 


\section{(a) Use by household access to ITNs}

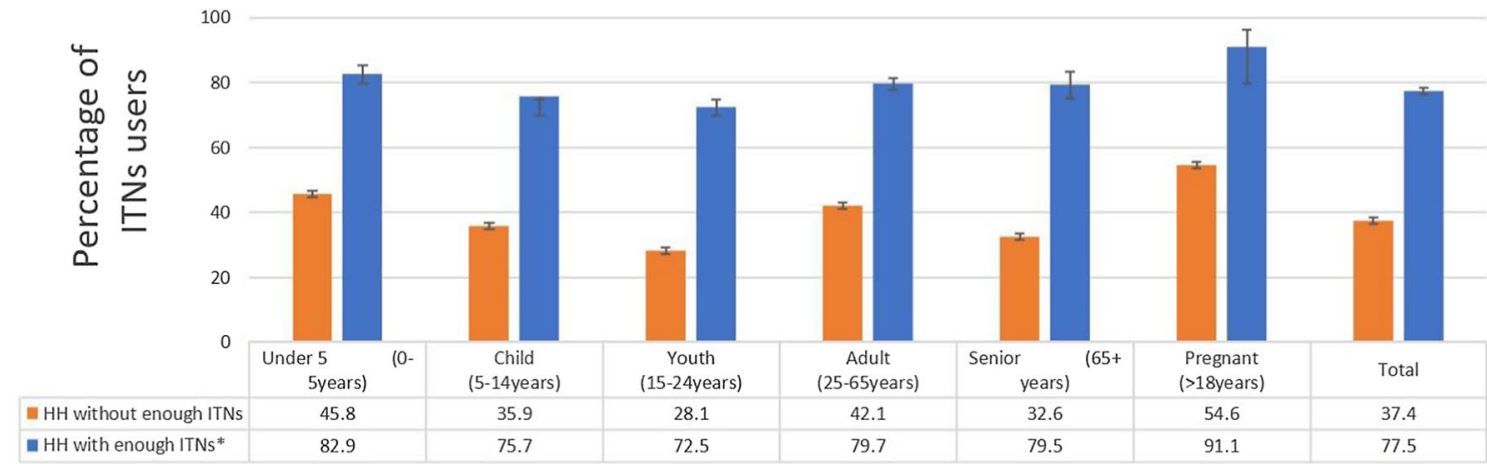

\section{(b) Percentage of users that slept alone under an ITN by household access to nets}

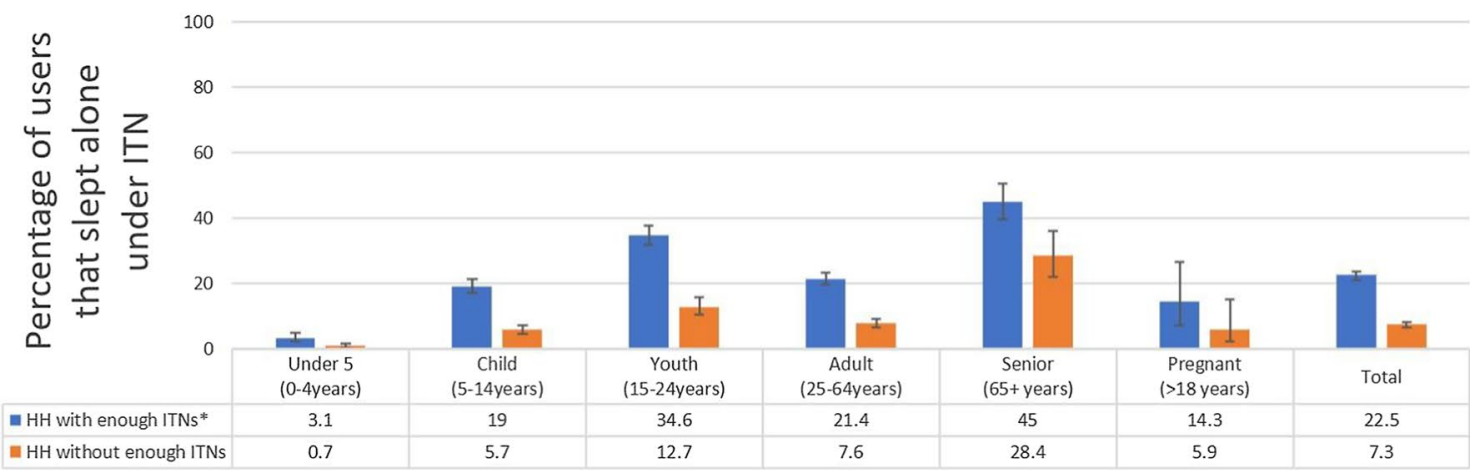

(c) User categories under ITNs by serviceability

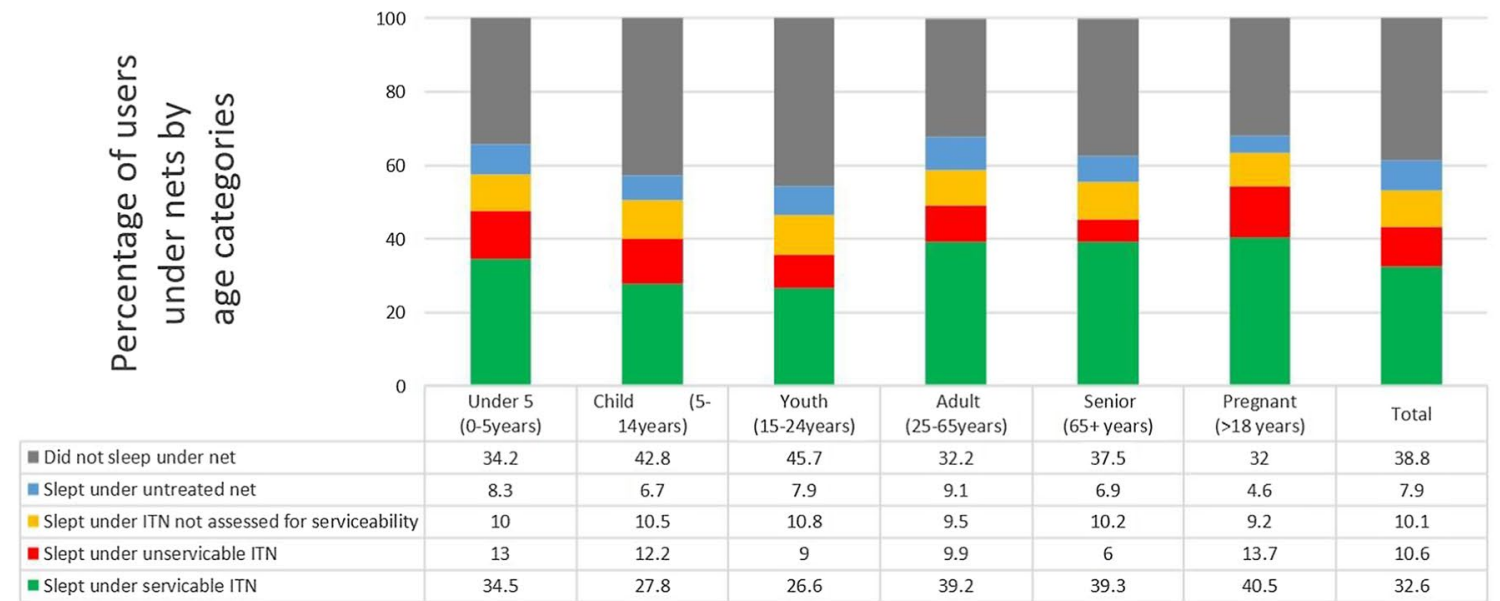

*Assuming each net was used by two people

Error bars represent the uncertainty of the corresponding point estimate $(95 \% \mathrm{Cl})$

Fig. 1 ITN use assessment by user categories and serviceability. a the denominator used is 7650 ITNs found in the participating households, $\mathbf{b}$ while some sleepers slept under an ITN their appropriate age could not be accounted for, c denomminator includes all 9178 nets found in households during the survey 
adults (39.2\%), seniors (39.3\%), and 5\% fewer children 5-14 (27.8\%), and 6\% fewer youths 15-24 (26.6\%) slept under a serviceable ITN (Fig. 1c). Pregnant women reported the highest use of nets irrespective of serviceability (54.2\%) followed by adults (49.2\%) and children under-5 years (47.5\%) (Fig. 1c). Children (5-14 years) and young adults (15-24 years) were less likely to sleep under an ITN and if they did sleep under an ITN it was more likely to be unserviceable (Fig. 1c).

Results of univariable and multivariable analyses exploring the consequences of net allocation on ITN serviceability are presented in Table 4 . The number of people that slept under an ITN, the age category of net users, and socio-economic status were all significantly associated with ITN serviceability $(p<0.001)$ in the univariate analysis. The odds of NetProtect ${ }^{\circledR}$ nets being serviceable was two times the odds of Olyset ${ }^{\circledR}$ nets 2.08 (95\% CI $1.68-2.58), p<0.001$. ITNs used by children (5-14 years) had lower odds of being serviceable compared to those used by under-fives 0.72 (95\% CI $0.56-0.93$ ), $p<0.001$. Controlling for net product and user characteristics (age, gender and socio-economic status), crowding was significantly associated with unserviceable ITNs $(p<0.001)$. Compared to one person under a net, having two people under the net reduced the odds of serviceability to OR 0.75 (95\% CI: 0.60-0.83) and having three people under the net further reduced the odds of serviceability to OR 0.50 (95\% CI: 0.40-0.63).

\section{Universal replacement campaign in Musoma}

A total of 398 households were visited in Musoma district by the study team in 2015, where 7 households were found with no nets. The average number of sleeping spaces per household was found to be 3.3 and the average number of people per household was 6.1. Forty-four per cent (95\% CI: $38.8-48.8 \%$ ) of households had at least one URC net with an average of 1.4 URC nets per household. Ten per cent (95\% CI: 9.2-12.6\%) of the households had enough URC nets; $23.6 \%$ (95\% CI 16.7-30.6\%) of the population in those households had access to a URC; $27.7 \%$ (95\% CI 25.9-29.5\%) of the population used a URC net the night before the survey (Additional file 2: Table S1). Of the 1,971 total nets identified in Musoma district, $48.4 \%$ were distributed by the study, $17.0 \%$ from URC, $1.9 \%$ from a shop/market, $0.9 \%$ from non-governmental/charity organizations, and $31.9 \%$ from other sources (unknown to the respondent at the time of the survey and/or could not be confirmed to be a study net as did not have a barcode). Overall, $84.1 \%$ of 1971 nets were used the night preceding the survey by $71.2 \%$ of the population, indicating a use: access ratio of 0.83 (Table 2).

\section{Houses with sufficient nets}

In households with sufficient nets in Musoma district, $85.0 \%$ of the nets used were study nets (Table 5). Adults (25-64 years) and children under 5 years were reported the highest users of study nets. Youths (15-24 years)

Table 3 Population ITN use by 3 or more people by household access

\begin{tabular}{|c|c|c|c|c|c|c|c|}
\hline & & \multicolumn{3}{|c|}{ Households with enough ITNs } & \multicolumn{3}{|c|}{ Households without enough ITNs } \\
\hline \multicolumn{2}{|c|}{$\begin{array}{l}\text { Number of households } \\
\text { with ITNs used previous } \\
\text { night }\end{array}$} & \multicolumn{3}{|l|}{1314} & \multicolumn{3}{|l|}{863} \\
\hline \multicolumn{2}{|c|}{$\begin{array}{l}\text { Number of nets found in } \\
\text { households }\end{array}$} & \multicolumn{3}{|l|}{5899} & \multicolumn{3}{|l|}{3288} \\
\hline \multicolumn{2}{|c|}{$\begin{array}{l}\text { Number of nets used by } \\
\text { three or more people }\end{array}$} & \multicolumn{3}{|l|}{519} & \multicolumn{3}{|l|}{824} \\
\hline \multicolumn{2}{|c|}{$\begin{array}{l}\% \text { of nets used by } 3 \text { or } \\
\text { more people }(95 \% \text { Cl) }\end{array}$} & \multicolumn{3}{|c|}{ 8.8\% (95\% Cl: 8.0-9.7\%) } & \multicolumn{3}{|c|}{$25.1 \%$ (95\% Cl: 23.0-27.3\%) } \\
\hline Age in years & $n_{1}$ & & $\mathrm{n}_{2}$ & $\begin{array}{l}\text { Crowded** } \\
(95 \% \mathrm{Cl})\end{array}$ & $n_{1}$ & $\mathrm{n}_{2}$ & $\begin{array}{l}\text { Crowded ** } \\
(95 \% \mathrm{Cl})\end{array}$ \\
\hline Under 5 & 612 & & 389 & $63.6(59.7-67.3)$ & 814 & 687 & $84.4(81.8-86.8)$ \\
\hline $5-14$ & 1446 & & 441 & $30.5(28.2-32.9)$ & 1256 & 756 & $60.2(57.4-62.8)$ \\
\hline $15-24$ & 945 & & 185 & $19.6(17.2-22.2)$ & 630 & 313 & $49.7(45.8-53.6)$ \\
\hline $25-64$ & 1880 & & 539 & $28.7(26.7-30.8)$ & 1391 & 844 & $60.7(58.1-63.2)$ \\
\hline \multirow[t]{2}{*}{$64+$} & 331 & & 34 & $10.3(7.4-14.0)$ & 155 & 38 & $24.5(18.4-31.9)$ \\
\hline & 5214 & & 1588 & $30.5(29.2-31.7)$ & 4246 & 2638 & $62.1(60.7-63.6)$ \\
\hline
\end{tabular}

\footnotetext{
* Assuming each net is used by 2 people

** Net use by 3 or more sleepers

$n_{1}$ Number of people who slept under net last night

$n_{2}$ Number of people who were crowded
} 
were the main users of nets from other sources when households had enough nets, while children (5-14 years) were the highest URC net users (Table 5).

\section{Houses without sufficient nets}

Sixty-four out of 398 households in Musoma district did not have sufficient nets. All of these households were among the lowest two SES groups. Majority of these household members were reported to have slept under a study net $(75.0 \%)$ the previous night in comparison to $13.0 \%$ under URC nets and $12.0 \%$ under nets acquired from other sources (Table 5). Among the study nets used by households that do not have enough nets, Olyset $^{\circledR}$ product was the most used at $36.0 \%$ (Table 5). Houses without enough nets had a lower percentage of use of URC nets at $13.0 \%$, compared to $18.9 \%$ of houses with enough nets and a lower proportion of nets from other sources at $12.0 \%$, compared to $35.3 \%$ of houses with enough nets.

\section{Discussion}

Twenty-two months post-ITN distribution, $57 \%$ of households still owned enough ITNs and $84 \%$ of the population had access to an ITN within their household, assuming each net was used by 2 household members. These results agree well with a multi-country survey assessment [39] and show that high population access can be achieved by distributing nets to cover sleeping spaces identified in households or limiting the number of nets a household can receive. Irrespective of the distribution approach, such as coverage of all sleeping spaces or one ITN for every 2 people, a low percentage $(<80 \%)$ of households with sufficient nets for all household members, will have ramifications for ITN durability. In Mozambique [40], assumptions on user characteristics, such as age and gender, to assess the likelihood of sharing a sleeping space were used by the NMCP to guide allocation of nets per sleeping spaces available in a household. This model was highly effective in achieving high access to households, but is logistically unrealistic for large countries without good census data. For Tanzania, it may be more practicable to deliver nets at a higher ratio than

Table 4 Univariable and multivariable analysis of factors associated with serviceability of study ITNs

\begin{tabular}{|c|c|c|c|c|c|c|}
\hline & \multirow[t]{2}{*}{$\mathrm{N}$} & \multirow{2}{*}{$\begin{array}{l}\text { Number serviceable, } \\
\mathrm{n}(\%)\end{array}$} & \multicolumn{2}{|l|}{ Crude estimates } & \multicolumn{2}{|c|}{ Adjusted estimates* } \\
\hline & & & OR $(95 \% \mathrm{Cl})$ & $p$-value & OR $(95 \% \mathrm{Cl})$ & $p$-value \\
\hline \multicolumn{7}{|c|}{ Number of people under net } \\
\hline 1 & 1254 & $1006(80.2)$ & 1 & \multirow[t]{3}{*}{$<0.001$} & 1 & \multirow[t]{3}{*}{$<0.001$} \\
\hline 2 & 866 & $611(70.6)$ & $0.60(0.46-0.77)$ & & $0.75(0.60-0.83)$ & \\
\hline $3+$ & 788 & $497(63.1)$ & $0.45(0.33-0.59)$ & & $0.50(0.40-0.63)$ & \\
\hline \multicolumn{7}{|c|}{ User characteristics } \\
\hline \multicolumn{7}{|c|}{ Age (years) } \\
\hline Under 5 & 450 & $312(69.3)$ & 1 & \multirow{5}{*}{$<0.001$} & 1 & \multirow{5}{*}{$<0.001$} \\
\hline $5-14$ & 786 & $493(62.7)$ & $0.74(0.58-0.95)$ & & $0.72(0.56-0.93)$ & \\
\hline $15-24$ & 392 & $286(73.0)$ & $1.19(0.88-1.61)$ & & $1.06(0.78-1.45)$ & \\
\hline $25-65$ & 1118 & $879(78.6)$ & $1.63(1.27-2.08)$ & & $1.29(0.99-1.68)$ & \\
\hline $65+$ & 162 & $144(88.9)$ & $3.54(2.08-6.01)$ & & $2.62(1.51-4.54)$ & \\
\hline \multicolumn{7}{|c|}{ Socio-economic status } \\
\hline Poorest & 640 & $479(74.8)$ & 1 & \multirow[t]{5}{*}{0.009} & 1 & \multirow[t]{5}{*}{0.012} \\
\hline Poor & 550 & $393(71.5)$ & $0.84(0.65-1.09)$ & & $0.85(0.66-1.11)$ & \\
\hline Middle & 510 & $365(71.6)$ & $0.85(0.65-1.10)$ & & $0.81(0.62-1.06)$ & \\
\hline Wealthy & 635 & $435(68.5)$ & $0.73(0.57-0.93)$ & & $0.71(0.55-0.91)$ & \\
\hline Wealthiest & 537 & $442(77.1)$ & $1.13(0.87-1.48)$ & & $1.09(0.83-1.43)$ & \\
\hline \multicolumn{7}{|l|}{ Gender } \\
\hline Male & 1338 & $951(71.1)$ & 1 & \multirow[t]{2}{*}{0.070} & 1 & \multirow[t]{2}{*}{0.081} \\
\hline Female & 1570 & $1163(74.1)$ & $1.16(0.99-1.37)$ & & $1.16(0.98-1.38)$ & \\
\hline \multicolumn{7}{|l|}{ Net product } \\
\hline Olyset ${ }^{\circledR}$ & 1520 & $1066(70.1)$ & 1 & \multirow[t]{3}{*}{$<0.001$} & 1 & \multirow[t]{3}{*}{$<0.001$} \\
\hline PermaNet $^{\circledR}$ & 1667 & $1317(79.0)$ & $1.26(1.04-1.53)$ & & $1.32(1.08-1.61)$ & \\
\hline NetProtect ${ }^{\circledR}$ & 1596 & 1349 (84.5) & $1.95(1.58-2.40)$ & & $2.08(1.68-2.58)$ & \\
\hline
\end{tabular}

\footnotetext{
* Adjusted for other factors in the Table
} 
1.8 to ensure all users, even those who sleep alone, have access to an ITN.

This study showed evidence that as the number of people sleeping under an ITN increases ('crowding'), the number of serviceable nets in a household decreases. Eighty per cent of household members were observed to sleep under a net when the person: net ratio was 3:1 and this decreased to $50 \%$ of the population using a net when 4 or more people slept under a single net, with the remaining $50 \%$ being left uncovered [30]. While the use: access ratio observed in Table 2 may vary due to season of data collection, the high $(>1)$ ratio indicates that as access to nets decreases within households, crowding increased, which in turn will hasten net damage and increase risk of malaria incidence. In Yemen, non-use of ITNs was associated with ownership of multiple damaged nets [41]. In Liberia [24], a 32\% reduction in ITN use was associated with increase in household size while having 3 or more nets was associated with increased odds of ITN use. Importantly, mosquitoes are more attracted to households with a large family [42], so family size does need to be considered in the design of ITN distribution campaigns. Higher parasitaemia was observed among those with low ITN use in Tanzania [43] while malaria incidence in Senegal [44] rose after the third year when ITN ownership had declined. Therefore, it may be more cost effective to distribute slightly too many nets rather than too few nets to ensure households have enough serviceable ITNs to cover the population, to slow the process of net damage as the protective effect of ITNs declines through time as nets accumulate damage [45].

Physical degradation of the net products was also observed to vary by product after 22 months of ownership. NetProtect ${ }^{\circledR}$ was two times more likely to be serviceable when compared to Olyset ${ }^{\circledR}$ in this setting. When compared to PermaNet ${ }^{\circledR}$, Olyset ${ }^{\circledR}$ nets have been observed to have more holes in both Mozambique [46], Zambia [47], Zanzibar [48], and mainland Tanzania [32]. In Madagascar [49], 55.6\% of NetProtect ${ }^{\circledR}$ ITNs were in good condition after a year when compared to Royal Sentry $^{\circledR}(56.8 \%)$ and Yorkool ${ }^{\circledR}(69.2 \%)$, which is lower than in the current study, indicating the importance of considering location when estimating ITN durability as cultural influences, net care and attitudes as well as the physical environment all impact on the expected life of ITNs. In fact, an analysis of United States President's Malaria Initiative country-surveys found that the variation of overall durability of ITNs was larger between countries than among net types, although the durability of net types does vary within countries [50,51]. A literature and data review by Koenker and Yukich [52] found that product attributes do not affect use, agreeing with this study which shows NetProtect ${ }^{\circledR}$ was used equally to the other products but was only found to be more durable in Tanzania. The Tanzania NMCP should consider procuring the most appropriate longer-lasting ITN product to be distributed to ensure the nets distributed last for the intended interval between campaigns.

Population access was $84.4 \%$ just prior to the URC campaign in the study population, with the exception of Musoma district which had already received campaign nets, and which in addition to study nets, increased access to $94.3 \%$. Unfortunately, despite the URC that was conducted August 2015 to January 2017, none of the participating districts recorded an increase in population access according to the TMIS [14] that was conducted October-December, 2017, 2 years after the first district received their URC nets (Ikupa Akim, pers. comm.). A $10 \%$ annual decrease in population access was also observed by Odufuwa et al. [53] in both Ulanga and Bagamoyo districts in Tanzania. These findings suggest that the current 4-year universal coverage distribution intervals are too widely spaced, not in line with WHO recommendations for mass distribution campaigns [11], and will provide sub-optimal impact of ITNs for malaria control in Tanzania. Mass distribution campaigns distribute one ITN for every 2 household members, and generally result in lower than recommended access so it may

Table 5 Net use by source of net in Musoma district

\begin{tabular}{|c|c|c|c|c|c|c|c|c|c|}
\hline & \multirow{2}{*}{$\begin{array}{l}\text { Number of } \\
\text { households }\end{array}$} & \multirow[t]{2}{*}{ Total nets } & \multirow{2}{*}{$\begin{array}{l}\text { Nets used } \\
\text { previous night } \\
(\%)\end{array}$} & \multicolumn{4}{|c|}{ Study nets N (\%) } & \multirow[t]{2}{*}{ URC N (\%) } & \multirow[t]{2}{*}{ Other N (\%) } \\
\hline & & & & Olyset $^{\circledR}$ & PermaNet ${ }^{\circledR}$ & NetProtect $^{\circledR}$ & Total study nets & & \\
\hline $\begin{array}{l}\text { Households } \\
\text { with } \\
\text { enough } \\
\text { ITNs* }^{*}\end{array}$ & 334 & 1833 & $1558(85.0)$ & $231(32.3)$ & $240(33.6)$ & $243(34.0)$ & $714(45.8)$ & $294(18.9)$ & $550(35.3)$ \\
\hline $\begin{array}{l}\text { Households } \\
\text { without } \\
\text { enough } \\
\text { ITNs }\end{array}$ & 64 & 145 & $100(72.5)$ & $27(36.0)$ & $25(33.0)$ & $23(30.7)$ & 75 (75.0) & $13(13.0)$ & $12(12.0)$ \\
\hline
\end{tabular}

* Assuming each net is used by 2 people 
be worth following WHO recommendation of 3-year intervals to maintain malaria control gains, in addition to selecting the optimal ITN for the Tanzanian setting. Fortunately, Tanzania has adopted continuous distribution channels through the antenatal and immunization clinics, and the school net programme [54], which will be essential to maintain universal coverage as recommended by WHO [11]. The school-net distribution programme is particularly important as the current study found that children of school age are most likely to be unprotected with either no net at all, or an unserviceable net and this age group is significant to malaria control as school-age children are an infectious reservoir [55-57]. That children of school age are most likely to be unprotected is not a new finding as it was shown as early as 2009 that they are not prioritized for ITNs [57]. However, it was seen that in houses with enough nets, families do not need to prioritize nets as all age groups are likely to have access to ITNs. It is, therefore, prudent to maximize household ITN access during mass campaigns to ensure that all household members use nets and are not forced to crowd under nets, which is associated with decreased net serviceability.

Increasing access to nets within a household increases net use, which in turn will eliminate inequalities between age and gender [29]. Contrary to the study by Tsuang et al. [30], where infants were prioritized to use new nets, in Musoma, children and youths had the highest use of newly acquired URC or nets from other sources. Therefore, while school-aged children were less prioritized to use existing study nets irrespective of the household's access to enough nets, they were accommodated by the arrival of new nets. Both studies observed that each targeted group was reached by its respective distribution mechanism (Tanzania National Voucher Scheme reached pregnant women and infants $[58,59]$ and the school net programme reached school-aged children [5, $54,60]$ ), while the lack of sufficient access to nets in the households left older children to use unserviceable nets or remain uncovered. The study recommends continued behaviour change communication messaging of yearround coverage for vulnerable populations, indirectly implying their prioritization when households do not have enough nets, and for neighbours to share ITNs if they have excess.

\section{Study limitations}

The study distributed one ITN for every sleeping space identified during enrolment instead of using the recommended practice of one ITN for every 2 household members. While this distribution mechanism may have prevented distribution of excess ITNs to household members without unique sleeping spaces, it biased household and population access to ITNs to higher levels than would be achieved by national campaigns from enrolment.

It is also important to note that the URC coincided with the general election season in Tanzania. This may have contributed to the lack of extensive distribution of ITNs in Musoma district and/or the delayed distribution of ITNs to populations prior to this study in order to prevent affiliation with any political party rally coinciding with a distribution date.

There is also a challenge in the definition and measurement of population access in assuming each ITN is used by 2 people. For example, if a 25 -years-old woman is living with her uncle and they have only one net, in principle as per MERG indicators for measuring household mosquito net distribution, population access is complete. However, in practice, these two people are unlikely to sleep under the same net, leaving one household member uncovered and population access incomplete. Therefore, this was a challenge while assessing population access that could not be changed or controlled.

While even torn nets still offer chemical protection against mosquitoes [61, 62], including unserviceable nets (which are extensively damaged), the calculation of population access overestimates the proportion of household members with access to a net that is fully protective within their household. A maximum of only 3 nets per household were assessed for their physical condition for logistical reasons. Although the 3 nets were randomly chosen, they potentially missed: (1) the most damaged nets in households; and, (2) how sleeping arrangements of the population were affected by the physical status of the other nets. Quantifying all the ITNs would further inform the prioritization of net use in larger households with more than 3 nets.

\section{Conclusion}

Twenty-two months post-ITN distribution, over $50 \%$ of sleeping spaces did not have access to a study net, despite complete coverage at baseline. However, the percentage of the population with access to ITNs was above the target of $80 \%$ while $57 \%$ of households had enough ITNs. The URC mass campaign helped to further maintain universal access to ITNs in Musoma district. These findings indicate that households hold on to their ITNs despite the arrival of new ones. Crowding under ITNs was associated with lower ITN serviceability most likely due to physical stress on the ITN fabric that causes physical damage to occur faster, thereby reducing the serviceable life of the net. When households have enough nets, around $80 \%$ of members from all age categories have access to a net. However, when there are insufficient nets, children (5-15 years) and youths (15-24 years) 
were least likely to use any ITN or have access to a serviceable ITN. This is of significant biological importance since school-aged children carry gametocytes that cause transmission of malaria from humans to mosquitoes and maintain malaria transmission. There is a need to refine delivery strategies to ensure households, including larger households, receive sufficient nets to cover all sleeping spaces. More frequent and more informed ITN distribution through keep-up strategies such as the school-net programme is essential to address these coverage inequalities and ensure continued protection against malaria transmission for all household members.

\footnotetext{
Abbreviations

GPS: Global positioning system; ITNs: Insecticide-treated nets; MERG: Roll Back Malaria Monitoring and Evaluation Reference Group; NMCP: National malaria control programme; pHI: Proportionate hole index; SES: Socio-economic status; TMIS: Tanzania Malaria Indicator Survey; URC: Universal replacement campaign; WHO: World Health Organization.
}

\section{Supplementary Information}

The online version contains supplementary material available at https://doi. org/10.1186/s12936-021-03686-2.

\section{Additional file 1. \\ Additional file 2: Table S1. Coverage of nets in Musoma district by net source.}

\section{Acknowledgements}

Tremendous gratitude to the entire SAVY team: field enumerators and district coordinators for their tireless efforts to interview all participating households. Special thanks to the ABCDR technicians who ensured all equipment for fieldwork was always fixed and ready for work.

\section{Authors' contributions}

HJO, LML, JM, and SJM conceived and designed the study. ZMM, DM collected the data. ZMM, CF, and JB analysed the data. ZMM wrote the manuscript. HJO, LML, JM, JB, WK, RM, IA, JL and SJM critically reviewed the manuscript. All authors read and approved the final drafts of this manuscript.

\section{Funding}

The study was funded by the Research Council of Norway under the ABCDR Project No: 220757.

\section{Availability of data and materials}

The datasets analysed in this current study are available from the corresponding author on reasonable request.

\section{Declarations}

\section{Ethics approval and consent to participate}

Ethical approval was obtained from the Ifakara Health Institute (Ref: IHI/RB/ No: 19-2013), the National Institute of Medical Research, Tanzania (Ref: NIMR/ $\mathrm{HQ} / \mathrm{R} .8 \mathrm{a} / \mathrm{Nol} \mathrm{I} / 285$ ) and the London School of Hygiene \& Tropical Medicine (Ref: 6333). The household questionnaire was administered upon written informed consent by interviewees above 18 years of age.

\section{Consent for publication}

This manuscript is published with the permission of the Director-General of the National Institute of Medical Research (NIMR), Tanzania.

\section{Competing interests}

The authors declare that that they have no competing interests.

\section{Author details}

${ }^{1}$ Ifakara Health Institute, Dar es Salaam, Tanzania. ${ }^{2}$ Department of Disease Control, Faculty of Infectious and Tropical Diseases, London School of Hygiene and Tropical Medicine, London WC1E 7HT, UK. ${ }^{3}$ College of Medicine and Veterinary Medicine, University of Edinburgh, Queen's Medical Research Institute, 47 Little France Crescent, Edinburgh EH16 4TJ, UK. ${ }^{4}$ Vector Control Product Testing Unit, Ifakara Health Institute, Ifakara, Tanzania. ${ }^{5}$ Epidemiology and Public Health Department, Swiss Institute of Tropical and Public Health, Soccinstrase 57, 4002 Basel, Switzerland. ${ }^{6}$ University of Basel, Petersplatz 1, 4003 Basel, Switzerland. ${ }^{7}$ University of Dar Es Salaam, Mbeya College of Health and Allied Sciences, Box 608, Mbeya, Tanzania. ${ }^{8}$ National Institute for Medical Research, Amani Research Centre, Muheza, Tanga, Tanzania. ${ }^{9}$ MRC Tropical Epidemiology Group, London School of Hygiene and Tropical Medicine, London WC1E 7HT, UK. ${ }^{10}$ Ministry of Health and Social Welfare, National Malaria Control Programme, Dar-es-Salaam, Tanzania. ${ }^{11}$ Faculty of Science and Technology, Norwegian University of Life Sciences, P.O. Box 5003, 1432 Ås, Norway. 12 Department of Microbiology, Faculty of Medicine, Khon Kaen University, Khon Kaen, Thailand.

Received: 17 September 2020 Accepted: 5 March 2021

Published online: 29 March 2021

\section{References}

1. Bhatt S, Weiss D, Cameron E, Bisanzio D, Mappin B, Dalrymple U, et al. The effect of malaria control on Plasmodium falciparum in Africa between 2000 and 2015. Nature. 2015:526:207-11.

2. Renggli S, Mandike R, Kramer K, Patrick F, Brown N, McElroy PD, et al. Design, implementaion and evaluation of a national campaign to deliver 18 million free long-lasting insecticidal nets to uncovered sleeping spaces in Tanzania. Malar J. 2013;12:85.

3. SwissTPH/NETCELL Project, Tanzania National Malaria Control Program. Mass Distribution of Long Lasting Insecticide Treated Nets: Tanzania 2015/2016. In: SwissTPH/Netcell Project, Tanzania National Malaria Control Programme, Dar-es-Salaam: 2017.

4. Bonner K, Mwita A, McElroy PD, Omari S, Mzava A, Lengeler C, et al. Design, implementation and evaluation of a national campaign to distribute nine million free LLINs to children under five years of age in Tanzania. Malar J. 2011;10:73.

5. Lalji S, Ngondi JM, Thawer NG, Tembo A, Mandike R, Mohamed A, et al. School distribution as keep-up strategy to maintain universal coverage of long-lasting insecticidal nets: implementation and results of a program in Southern Tanzania. Glob Health Sci Pract. 2016:4:251-63.

6. Swiss Tropical and Public Health Institute. NETCELL PROJECT: Supporting the Tanzanian National Malaria Control Programme in the Fight Against Malaria. Dar-es-Salaam2017.

7. WHO. The World Malaria Report 2019. Geneva: World Health Organization, 2019.

8. Chacky F, Runge M, Rumisha SF, Machafuko P, Chaki P, Massaga JJ, et al. Nationwide school malaria parasitaemia survey in public primary schools, the United Republic of Tanzania. Malar J. 2018;17:452.

9. Management Sciences for Health. Community Health Volunteers Combat Malaria in Madagascar Madagascar: Medium; 2017 [updated 06.10.2017; cited 2018 05.03.2018]. Available from: https://medium.com/@MSHHe althlmpact/community-health-volunteers-combat-malaria-in-madag ascar-da598674ad85.

10. WHO. Recommendations for achieving universal coverage with longlasting insecticidal nets in malaria control. Geneva: World Health Organization, 2014.

11. WHO. Achieving and maintaining universal coverage with long-lasting insecticidal nets for malaria control. Geneva: World Health Organization, 2017.

12. WHO. Estimating population access to ITNs versus quantifying for procurement for mass campaigns. Geneva: World Health Organization, 2014.

13. WHO. World Malaria Report 2019. Geneva: World Health Organization, 2019 
14. Ministry of Health Community Development G, Elderly and Children, Ministry of Health, National Bureau of Statistics, Office of the Chief Government Statistian, ICF. Tanzania Malaria Indicator Survey 2017 - Final Report. Dar es Salaam, Tanzania, Zanzibar: MoHCDEC, MoH, NBS, OCGS, ICF; 2018.

15. Bhatt S, Weiss DJ, Mappin B, Dalrymple U, Cameron E, Bisanzio D, et al. Coverage and system efficiencies of insecticide-treated nets in Africa from 2000 to 2017. eLife. 2015;4:e09672.

16. Kilian A. How long does a long-lasting insecticidal net last in the field? Public Health J. 2010;21:43-7.

17. Kilian A, Byamukama W, Pigeon O, Atieli F, Duchon S, Phan C. Long-term field performance of a polyester-based long-lasting insecticidal mosquito net in rural Uganda. Malar J. 2008;7:49.

18. Kilian A, Byamukama W, Pigeon O, Gimnig J, Atieli F, Koekemoer L, et al. Evidence for a useful life of more than three years for a polyester-based long-lasting insecticidal mosquito net in Western Uganda. Malar J. 2011;10:299.

19. Loll D, Berthe S, Faye SL, Wone I, Koenker H, Arnold B, et al. User-determined end of net life in Senegal: a qualitative assessment of decisionmaking related to the retirement of expired nets. Malar J. 2013;12:337.

20. Loha E, Tefera K, Lindtjorn B. Freely distributed bed-net use among Chano Mille residents, south Ethiopia: a longitudinal study. Malar J. 2013;12:23.

21. Baume $C A$, Reithinger $R$, Woldehanna $S$. Factors associated with use and non-use of mosquito nets owned in Oromia and Amhara regional states. Ethiopia Malar J. 2009;8:264

22. Kleinschmidt I, Bradley J, Knox TB, Mnzava AP, Kafy HT, Mbogo C, et al. Implications of insecticide resistance for malaria vector control with longlasting insecticidal nets: a WHO-coordinated, prospective, international, observational cohort study. Lancet Infect Dis. 2018;18:640-9.

23. Koenker H, Killian A. Recalculating the net use gap: a multi-country comparison of ITN use versus ITN access. PLOS ONE. 2014:9:e97496.

24. Babalola S, Ricotta E, Awantang G, Lewicky N, Koenker H, Toso M. Correlates of intra-household ITN use in Liberia: a multilevel analysis of household survey data. PLoS ONE. 2016;11:e0158331.

25. Baume CA, Marin MC. Intra-household mosquito net use in Ethiopia, Ghana, Mali, Nigeria, Senegal, and Zambia: are nets being used? Who in the household uses them? Am JTrop Med Hyg. 2007;77:963-71.

26. Fernando SD, Abeyasinghe RR, Galappaththy GN, Gunawardena N, Ranasinghe AC, Rajapaksa LC. Sleeping arrangements under long-lasting impregnated mosquito nets: differences during low and high malaria transmission seasons. Trans R Soc Trop Med Hyg. 2009;103:1204-10.

27. Mboma ZM, Overgaard HJ, Moore S, Bradley J, Moore J, Massue DJ, et al. Mosquito net coverage in years between mass distributions: a case study of Tanzania, 2013. Malar J. 2018;17:100

28. Gonahasa S, Maiteki-Sebuguzi C, Rugnao S, Dorsey G, Opigo J, Yeka A, et al. LLIN Evaluation in Uganda Project (LLINEUP): factors associated with ownership and use of long-lasting insecticidal nets in Uganda: a crosssectional survey of 48 districts. Malar J. 2018;17:421.

29. Olapeju B, Choiriyyah I, Lynch M, Acosta A, Blaufuss S, Filemyr E, et al. Age and gender trends in insecticide-treated net use in sub-Saharan Africa: a multi-country analysis. Malar J. 2018;17:423.

30. Tsuang A, Lines J, Hanson K. Which family members use the best nets? An analysis of the condition of mosquito nets and their distribution within households in Tanzania. Malar J. 2010;9:211.

31. Lorenz L, Overgaard H, Massue D, Mageni Z, Bradley J, Moore J, et al. Investigating mosquito net durability for malaria control in Tanzania Attrition, Bioefficacy, Chemistry, Degradation and insecticide Resistance (ABCDR): study Protocol. BMC Public Health. 2014;14:1266.

32. Lorenz LM, Bradley J, Yukich J, Massue DJ, Mboma ZM, Pigeon O, et al. Comparative functional survival and equivalent annual cost of three long lasting insecticidal net (LLIN) products in Tanzania: a three-year prospective cohort study of LLIN attrition, physical integrity, and insecticidal activity. PLoS Med. 2020;17:e1003248.

33. Carnevale P, Bitsindou P, Diomande L, Robert V. Insecticide impregnation can restore the efficiency of torn bed nets and reduce man-vector contact in malaria endemic areas. Trans R Soc Trop Med Hyg. 1992;86:362-4.

34. Randriamaherijaona S, Briët OJ, Boyer S, Bouraima A, N'Guessan R, Rogier C, et al. Do holes in long-lasting insecticidal nets compromise their efficacy against pyrethroid resistant Anopheles gambiae and Culex quinquefasciatus? Results from a release-recapture study in experimental huts. Malar J. 2015;14:332
35. WHO. Guidelines for monitoring the durability of long-lasting insecticidal mosquito nets under operational conditions. Geneva: World Health Organization, 2011.

36. WHO. Estimating functional survival of long-lasting insecticidal nets from field data. Vector Control Technical Expert Group Report to MPAC September 2013. Geneva: World Health Organization.

37. Measure Evaluation, DHS Program, President's Malaria Initiative, RBM Partnership, UNICEF, WHO. Household survey indicators for malaria control 2013 [cited 2015 10/05/2015]. Available from: http://www.malariasurveys. org/documents/Household\%20Survey\%20Indicators\%20for\%20Malaria\% 20Control.pdf.

38. Measure Evaluation, The Demographic and Health Surveys Program, President's Malaria Initiative, Roll Back Malaria Partnership, United Nations Children's Fund, WHO. Household Survey Indicators for Malaria Control. Rockville. MD: Roll Back Malaria; 2018. p. 2018.

39. Koenker H, Arnold F, Ba F, Cisse M, Diouf L, Eckert E, et al. Assessing whether universal coverage with insecticide-treated nets has been achieved: is the right indicator being used? Malar J. 2018;17:355.

40. Plucinski MM, Chicuecue S, Macete E, Chambe GA, Muguande O, Matsinhe $\mathrm{G}$, et al. Sleeping arrangements and mass distribution of bed nets in six districts in central and northern Mozambique. Trop Med Int Health. 2015;20:1685-95.

41. Al-Eryani SMA, Mahdy MAK, Al-Mekhlafi AM, Abdul-Ghani R. Access to and use of long-lasting insecticidal nets and factors associated with non-use among communities in malaria-endemic areas of Al Hudaydah governorate in the Tihama region, west of Yemen. Malar J. 2017;16:244.

42. Kaindoa EW, Mkandawile G, Ligamba G, Kelly-Hope LA, Okumu FO. Correlations between household occupancy and malaria vector biting risk in rural Tanzanian villages: implications for high-resolution spatial targeting of control interventions. Malar J. 2016;15:199.

43. Khatib RA, Chaki PP, Wang D-Q, Mlacha YP, Mihayo MG, Gavana T, et al. Epidemiological characterization of malaria in rural southern Tanzania following China-Tanzania pilot joint malaria control baseline survey. Malar J. 2018;17:292.

44. Wotodjo AN, Doucoure S, Diagne N, Sarr FD, Parola P, Gaudart J, et al. Another challenge in malaria elimination efforts: the increase of malaria among adults after the implementation of long-lasting insecticidetreated nets (LLINs) in Dielmo. Senegal Malar J. 2018;17:384.

45. Janko MM, Churcher TS, Emch ME, Meshnick SR. Strengthening longlasting insecticidal nets effectiveness monitoring using retrospective analysis of cross-sectional, population-based surveys across sub-Saharan Africa. Sci Rep. 2018;8:17110.

46. Morgan J, Abílio AP, do Rosario Pondja M, Marrenjo D, Luciano J, Fernandes $\mathrm{G}$, et al. Physical durability of two types of long-lasting insecticidal nets (LLINs) three years after a mass LLIN distribution campaign in Mozambique, 2008-2011. Am JTrop Med Hyg. 2015;92:286-93.

47. Tan KR, Coleman J, Smith B, Hamainza B, Katebe-Sakala C, Kean C, et al. A longitudinal study of the durability of long-lasting insecticidal nets in Zambia. Malar J. 2016;15:106.

48. Haji KA, Khatib BO, Obi E, Dimoso K, Koenker H, Babalola S, et al. Monitoring the durability of the long-lasting insecticidal nets Olyset ${ }^{\circledR}$ and PermaNet ${ }^{\circledR} 2.0$ in similar use environments in Zanzibar. Malar J. 2020;19:187.

49. Randriamaherijaona S, Raharinjatovo J, Boyer S. Durability monitoring of long-lasting insecticidal (mosquito) nets (LLINs) in Madagascar: physical integrity and insecticidal activity. Parasit Vectors. 2017;10:564.

50. Kilian A, Abilio A, Obi E, Khamis A, Mansiangi P, Thein S, et al. Standardized monitoring of durability of Long-lasting Insecticidal Nets in five countries in Africa and Asia. American Society of Tropical Medicine and Hygiene 2018: Poster.

51. Briet O, Koenker H, Norris L, Wiegand R, Vanden Eng J, Thackeray A, et al. Attrition, physical integrity and insecticidal activity of long-lasting insecticidal nets in sub-Saharan Africa and modelling of their impact on vectorial capacity. Malar J. 2020;19:310.

52. Koenker $\mathrm{H}$, Yukich JO. Effect of user preferences on ITN use: a review of literature and data. Malar J. 2017;16:233.

53. Odufuwa OGO, Ross A, Mlacha YP, Juma O, Mmbaga S, Msellemu D, et al. Factors associated with access to insecticide-treated nets and use of house modification in Bagamoyo and Ulanga districts, Tanzania. medRxiv. 2019.

54. Stuck L, Lutambi A, Chacky F, Schaettle P, Kramer K, Mandike R, et al. Can school-based distribution be used to maintain coverage of long-lasting 
insecticide-treated bed nets: evidence from a large scale programme in southern Tanzania? Health Policy Plan. 2017;32:980-9.

55. Coalson JE, Walldorf JA, Cohee LM, Ismail MD, Mathanga D, Cordy RJ, et al. High prevalence of Plasmodium falciparum gametocyte infections in school-age children using molecular detection: patterns and predictors of risk from a cross-sectional study in southern Malawi. Malar J. 2016;15:527.

56. Coalson JE, Cohee LM, Buchwald AG, Nyambalo A, Kubale J, Seydel KB, et al. Simulation models predict that school-age children are responsible for most human-to-mosquito Plasmodium falciparum transmission in southern Malawi. Malar J. 2018;17:147.

57. Noor A, Kirui V, Brooker S, Snow R. The use of insecticide treated nets by age: implications for universal coverage in Africa. BMC Public Health. 2009;9:369.

58. NMCP Tanzania. Tanzania National Voucher Scheme (2004 to date). 2014.

59. Kramer K, Mandike R, Nathan R, Mohamed A, Lynch M, Brown N, et al. Effectiveness and equity of the Tanzania National Voucher Scheme for mosquito nets over 10 years of implementation. Malar J. 2017;16:255.
60. Elisaria E, Stuck L, Geubbels E, Festo C, Chaky F, Nice J, et al. Evaluation of the School Net distribution Program Round 4 (SNP4): Technical Report. 2017.

61. Massue DJ, Moore SJ, Mageni ZD, Moore JD, Bradley J, Pigeon O, et al. Durability of Olyset campaign nets distributed between 2009 and 2011 in eight districts of Tanzania. Malar J. 2016;15:176.

62. Solomon T, Loha E, Deressa W, Balkew M, Gari T, Overgaard HJ, et al. Bed nets used to protect against malaria do not last long in a semi-arid area of Ethiopia: a cohort study. Malar J. 2018;17:239.

\section{Publisher's Note}

Springer Nature remains neutral with regard to jurisdictional claims in published maps and institutional affiliations.
Ready to submit your research? Choose BMC and benefit from:

- fast, convenient online submission

- thorough peer review by experienced researchers in your field

- rapid publication on acceptance

- support for research data, including large and complex data types

- gold Open Access which fosters wider collaboration and increased citations

- maximum visibility for your research: over $100 \mathrm{M}$ website views per year

At BMC, research is always in progress.

Learn more biomedcentral.com/submissions 